\section{Management of threatened abortion}

Advising a woman who bleeds early in her pregnancy is not always easy, for the outcome of such a threatened abortion is less closely correlated to the amount of bleeding than might be imagined. Pain is a more reliable indication that abortion is inevitable or incomplete, and often an accurate diagnosis can be made without difficulty by any doctor prepared to make a vaginal examination. In the absence of clear signs, however, he faces a diagnostic watershed; and if such a patient is admitted to hospital an early decision is economically and socially, as well as medically, desirable.

The most useful aid to diagnosis is the immunological pregnancy test. Its universal availability and dependability have caused a minor revolution in gynaecology in recent years (besides freeing countless small rodents and amphibians for better things). Its accuracy depends on careful technique with good illumination and intelligent interpretation, taking account of both the clinical presentation and the inherent limitations of the test itself. If negative, the test should be confirmed on an early morning urine specimen. If positive, it may be repeated as often as desired at little cost, except in terms of hospital accommodation-for trophoblast can remain viable in a non-progressing pregnancy for days or even weeks. Many workers have sought to resolve this problem with further investigations. Assays of total urinary oestrogens, of pregnanediol, or of chorionic gonadotrophin are technically difficult and in practice offer little more than the basic pregnancy test. ${ }^{1}$

Among the alternatives, ultrasonography appears to have much to commend it. Duff claims that, with a knowledge of the menstrual history, it is possible to diagnose virtually all cases of blighted ovum, missed abortion, or hydatidiform mole by a single sonar examination; though paradoxically he adds that if such diagnoses are to be certain the menstrual history should be ignored and the normality or otherwise of the pregnancy assessed on sonar evidence alone. That, however, implies serial studies at intervals of one to two weeks, thereby defeating the clinician's objective of an early decision on whether to send his patient home. The critical findings include the presence or absence of an embryo or fetal heart beat, the integrity and situation of the gestation sac, and an estimate of its size. Recent studies by Robinson ${ }^{2}$ have shown the value of calculating changes in the volume of the gestation sac itself.

Many may believe that the observer factor in sonar studies is of paramount importance. Few would question their accuracy in expert hands; but what clinician has not experienced frustration from logistical delays or mechanical failures and has not grown wary of inexperienced reporting? Individual evaluation, with direct contact between the clinician and sonographer, is of paramount importance in these cases. Possibly the answer lies elsewhere. Virtually every maternal system changes in pregnancy, and many lend themselves to accurate biochemical assessment. Of particular interest is the recent study of thyroid function by Winikoff and Malinek, ${ }^{3}$ who suggested that the absence of the characteristic gestational changes in thyroid profile may indicate a failing pregnancy: unfortunately not all individual results in women who aborted fell outside the normal pregnancy range. Of greater concern is their suggestion that thyroid replacement therapy might be of value, but such medication could not be justified in pregnancy other than as a carefully controlled double-blind trial.
Perhaps the solution to the diagnostic problem lies with the family doctor. There is little concrete evidence that admission to hospital materially improves the outcome in patients with early threatened abortion; and those with early missed abortions can be managed as outpatients by a sympathetic clinician until the diagnosis is clarified either by fetal heart detector or pregnancy test-or even simply by patient observation.

1 Duff, G B, British Fournal of Obstetrics and Gynaecology, 1975, 82, 858. 2 Robinson, H P, British fournal of Obstetrics and Gynaecology, 1975, 82, 849.

3 Winikoff, D, and Malinek, M, British Fournal of Obstetrics and Gynaecology, $1975,82,760$.

\section{Powell on private practice}

Last week saw yet another wave of industrial action by doctors objecting to the Government's proposed legislation on private practice, 1 with the predictable "counter-action" by some ancillaries, entrenching attitudes still further in this destructive confrontation. Surely by now the Department of Health can be left in no doubt that a substantial number of hospital doctors have genuine, deeply felt objections to the proposals. Others may be indifferent; but very few indeed seem to support the legislation in either its content or its timing. In these circumstances imposing legislation without the consent of the profession might be justified if there were a convincing case on the grounds of practical or economic necessity-which there is not; or if there had been manifest abuse of the current arrangements-but again there has not been; or if there were an overwhelming public demand for the abolition of NHS pay-bedsbut the opinion polls suggest that most people are content with the present state of affairs.

So the Government's case rests on its political convictions, and one may reasonably ask what the outcome is likely to be. On that point a fresh and unexpected voice is that of $\mathrm{Mr}$ Enoch Powell, whose views on the relation between the NHS and Government, first published in 1967, have been reprinted with an additional chapter on recent events in Medicine and Politics: 1975 and After. $^{2}$ He warns that the current proposals could do "what seemed impossible ten years ago, namely, re-establish a genuine private sector in medicine." Once the pay-beds have gone from State hospitals, he argues, the position of part-time consultants is bound more and more to appear anomalous, leading to growing pressure on them to convert to full time. The final result seems likely to be one of two extremes: either the development of quite distinct public and private sectors with two separate medical careers existing side by side, or a comprehensive State monopoly imposed by a legal ban on any form of private medicine.

With all-its defects-and they are becoming more serious ${ }^{3}$ the NHS as presently constituted seems likely to give the community a better service than either of the possibilities envisaged by $\mathrm{Mr}$ Powell. For those who believe in and care for the NHS these arguments provoke only frustration and depression, for the decisions that need to be taken on priorities, planning, and organisation are being postponed or neglected in the pursuit of a dangerous, unnecessary, and unjustifiable piece of political dogma.

\footnotetext{
${ }^{1}$ British Medical fournal, 1976, 1, 1024.

2 Powell, J Enoch, Medicine and Politics: 1975 and After. Tunbridge Wells, Pitman Medical, 1976.

${ }^{3}$ British Medical fournal, 1976, 1, 787.
} 